\title{
Characterization of uses of trigonometric notions in Mechatronics Engineering from Mathematics Education
}

\section{Caracterización de usos de las nociones trigonométricas en la Ingeniería Mecatrónica desde la Matemática Educativa}

\author{
TORRES-CORRALES, Diana del Carmen†** \& MONTIEL-ESPINOSA, Gisela
}

Departamento de Matemática Educativa del Centro de Investigación y Estudios Avanzados del Instituto Politécnico Nacional

ID $1^{\text {st }}$ Author: Diana del Carmen, Torres-Corrales / ORC ID: 0000-0002-0057-5336, CVU CONACYT ID: 634113

ID $1^{\text {st }}$ Coauthor: Gisela, Montiel-Espinosa / ORC ID: 0000-0003-1670-9172, CVU CONACYT ID: 94734

DOI: $10.35429 /$ EJS.2019.10.6.9.21

Received April 08, 2019; Accepted June 30, 2019

\begin{abstract}
From the Socioepistemological Theory we propose that even with the curricular articulation presented in school programs of Engineering it exists a disarticulation of uses of mathematical knowledge, this is displayed more emphatically when a student takes professionalizing courses. We proposed the research question of: what uses of trigonometric notions are given in Mechatronics Engineering when students solve problems in Robotics? we use the Socioepistemological Theory in tandem with the ethnographic method to identify and characterize them in their cultural framework. By the delimitation of the study to a community of Mechatronics Engineering in a Mexican university and the direct kinematics problem in the subject of Industrial Robotics, we characterize that trigonometric notions are given an arithmetic, metric, quantitative and algebraic usage, and by them, the Trigonometry acquires more significates aided by the construction of visual references that allow the mathematical modelling that was done, and from which we recognize in the pseudo-concrete models (drawing and kinematic schemes) the reason to be for Trigonometry as a tool for Robotics: the determination of the position in a circle or circular sector.
\end{abstract}

Mathematics Education, Engineering education, Trigonometry

\section{Resumen}

Desde la Teoría Socioepistemológica plateamos que aún con la articulación curricular que presentan los programas de Ingeniería existe una desarticulación de usos del conocimiento matemático, que se manifiesta con mayor énfasis cuando el estudiante cursa las asignaturas profesionalizantes. Para dar cuenta de ello se planteó la pregunta de investigación: ¿qué usos de las nociones trigonométricas se dan en la Ingeniería Mecatrónica cuando los estudiantes resuelven problemas de la Robótica?, y en articulación con la teoría, empleamos el método etnográfico para identificarlos y caracterizarlos en su marco cultural. Al delimitar el estudio a una comunidad de Ingeniería Mecatrónica de una universidad mexicana, y al problema cinemático directo de la asignatura de Robótica Industrial, caracterizamos que se dan los usos aritmético, métrico, cuantitativo y algebraico de las nociones trigonométricas, y de los cuales la Trigonometría adquiere más significados gracias a la construcción de referentes visuales que permiten modelar el problema en el espacio; asimismo documentamos el proceso de modelación matemática que hicieron y del cual reconocemos en los modelos pseudo concretos (dibujos y esquemas cinemáticos) la razón de ser de la Trigonometría como herramienta de la Robótica: determinación de la posición en la circularidad o sector circular.

Matemática Educativa, Formación de ingenieros, Trigonometría

Citation: TORRES-CORRALES, Diana del Carmen \& MONTIEL-ESPINOSA, Gisela. Characterization of uses of trigonometric notions in Mechatronics Engineering from Mathematics Education. Journal-Spain. 2019. 6-10: 9-21

\footnotetext{
* Correspondence to Author (diana.torres@ cinvestav.mx)

$\dagger$ Researcher contributing as first author.
} 


\section{Introduction}

Engineering is distinguished by design, which it develops through models (diagrams, tables, mathematical expressions, etc.) that allow engineers to represent, systematize, analyze and communicate their work (Bissell and Dillon, 2012). That is why modeling has been the subject of study for the academic training of engineers from various disciplines, including Mathematics Education, a discipline whose object of study is the didactic phenomena related to the teaching and learning of mathematics.

In research in Mathematics Education, mathematical modeling has been identified as the main competence that an engineering student must have (Faulkner, Earl and Herman, 2019). However, its complexity is recognized to develop mathematical modeling from the Mathematics classroom. For example, Langereis, $\mathrm{Hu}$ and Feijs (2013) reported a mathematical modeling experience in the Microcontroller subject of an Industrial Design Engineering program, from a competency-based learning approach and in a project-oriented environment; where the project was the design of a game.

To achieve this, the researchers required an inverted curricular proposal, finding that the modeling that goes from design to the model the opposite case of the traditional curriculum that goes from the mathematical problem to the engineering problem - links mathematical and disciplinary knowledge, and also allows a more robust understanding problem.

The curricular adjustment proposed by this authors has complex implications and, we believe, must be the product of an interdisciplinary work in which the various actors involved in the Engineering training process participate. However, in the background seems to continue the criticism of Herrera (1990) towards the orthodox curriculum model that segments the subjects in Basic Sciences, Engineering Sciences and Professionalization.

Our research does not seek a discussion about the curricular structure, but it does recognize a problem that can be linked to the way in which mathematics is put into use in each of these curricular blocks.
Specifically, in professionalizing subjects, we have identified a mathematical disarticulation in three recurring situations: (1) the student does not recognize mathematics, (2) the student remembers mathematics but does not use it because he does not master the algorithms associated with it and (3) Given the two previous situations, the Engineering teacher gives a review of the necessary mathematics in his subject, in order to reduce the drop-out and rejection rate.

Hence, we propose, even with a curricular articulation, a disarticulation of uses of mathematical knowledge does not facilitate the processes of mathematical modeling in professionalizing subjects. Where it becomes indispensable to understand what mathematics is put into use and how it is put into use in the Engineering of interest, to propose what to teach and how to teach it, in Basic Sciences, before deciding when to teach it.

\section{Mathematics for Engineering}

Our research is located in the Socioepistemological Theory (ST), specifically in the studies of the culturally situated uses of mathematical knowledge in Engineering. So far, we have identified three strategies to demonstrate and address this mathematical disarticulation: historical-epistemological analysis, the staging of learning situations and studies of homework in the classroom.

In the historical-epistemological analysis the emergence of a mathematical knowledge is recognized in a selected original work; the social and cultural circumstances of the time are identified, the author's mathematical activity is reconstructed, the value of the use of knowledge around the problem that was solved and the elements that allowed to construct meanings are identified.

A study in this strategy found that in the works of three scientists in the electrical area the use of the notion of steady state is transversal to them, but in the teaching of Electrical Engineering the notion is not discussed. This, as reported in (Hinojos and Farfán, 2017) causes its nature to darken and limited meanings are promoted around the mathematical notion of steady state. 
In the strategy of staging learning situations, a controlled design is developed that is applied extra-class to a group of students; This design is based on historical-epistemological analysis, which contrasts the mathematical activity of students in order to recognize the invariant elements that allow the construction of uses and meanings related to mathematical knowledge. A study in this strategy (MendozaHiguera, Cordero, Solís and Gómez, 2018) found that in the problem of fluid accumulation of a dam in Civil Engineering, mathematical activity is oriented to establish the trend behaviors through simulations, while that in the Mathematics subject it is limited to calculate, in an analytical and algebraic way, the solution of the differential equation.

In the study of classroom task, the researcher accompanies (in person or with video recording) in their classes to students and the teacher to study situations of their discipline, in order to understand the use and meaning they give to mathematical knowledge in the problem they solve, generally in contexts of Engineering Sciences and Applied Engineering; and later contrast the mathematical activity that occurs with its respective historical-epistemological analysis. A study in this strategy (Tuyub and Buendia, 2017) found that in the didactic component of the construction and environmental problems of a Master's Degree in Engineering, there are two uses of linear Cartesian graphs: organize information and show procedures and techniques, giving a meaning of the context to the slope and the order of origin; none of which work in the Mathematics subjects.

From these studies, it is recognized that there is a mathematical disarticulation that is attributed to a teaching, in Basic Sciences, that has privileged the use of formulas on the nature of mathematical knowledge (origin, conditions to be used and need to respond, among others). We recognize that, although this teaching has allowed learning, from our theoretical vision we seek to broaden these meanings with the intention of reducing this disarticulation.

\section{Research Problem}

Our research proposes the study of trigonometric knowledge put into use in Engineering, and from the review of some plans and programs of a Mexican university, we delimit research at three levels.
First, we chose the Mechatronics Engineering program because it shows the largest number of trigonometric content in their subjects. Second, we select a professionalizing subject, Industrial Robotics, because its contents show curricular articulation with the previous subjects (Engineering Sciences and Basic Sciences). Third, from the problems that are solved in the professionalizing subject we choose the direct kinematic problem because it illustrates the mathematical modeling process that it reports (Rodríguez-Gallegos, 2010): it transits between the real-pseudo concretemathematical domains; pseudo concrete models are elaborated (drawings, sketches, etc.) that allow to take the variables of interest of the real situation and from them mathematical models are constructed (graphical, numerical, algebraic, analytical, etc.) that allow to solve the situation, which is subsequently validated and confronted with disciplinary knowledge and the real situation.

With these delimitations, the research question was raised: what uses of trigonometric notions occur in Mechatronics Engineering when students solve Robotics problems?, and we use the ethnographic method to identify and characterize them in their cultural framework.

\section{Theoretical considerations}

Under the positioning of the Socioepistemological Theory, we attribute the identified mathematical disarticulation to the limitation of uses and meanings promoted by the School Mathematics discourse (SMd). The SMd is a theoretical construct that explains the forms of communication and collective agreements that structure mathematical knowledge as an absolute truth, with a particular procedure to access it through its representations, and therefore, with the admission of unique meanings (Cantoral et al., 2006).

Therefore, the theory is that the social construction of mathematical knowledge and its institutional diffusion is proposed as an object of study (Cantoral and Farfán, 2003); the social refers to the invariant practices that accompany the use of mathematical knowledge, and secondarily, group interaction and situational conditions. 
It is assumed by the use of mathematical knowledge to "the ways in which a certain notion is used or adopted in a specific context" (Cabañas, 2011, p. 75), "whether the subject is aware of it or not, manipulates explicitly or implicitly, or that uses typically school or context-specific representations" (Rotaeche, 2012, p. 27).

Therefore, the theory considers that only in the use of mathematical knowledge are relative, contextual and functional meanings generated to the particular scenario, which will be in constant construction by the human group as they are used to solve different problems, what they call the principle of progressive significance or resignification (Cantoral y Farfán, 2003).

One way to study the use mof mathematical knowledge is to recognize or analyze the dependence of the context through three levels: the cultural, the situational and the significance; what he calls contextualized rationality principle. The cultural context gives pertenence to human groups because their dominance in the behavior and social interactions of the subjects is recognized; the situational context recognizes the influence of time, place and conditions where the mathematical activity is carried out, these conditions are determined by the problem or can be established with the design of learning situations; and the context that gives form and meaning to the mathematics at stake, we call it context of meaning. The ST explains the social construction of mathematical knowledge through the nesting model of practices (figure 1), which is composed of an organization of practices that accompany the use of mathematical knowledge and increase complexity at each level.

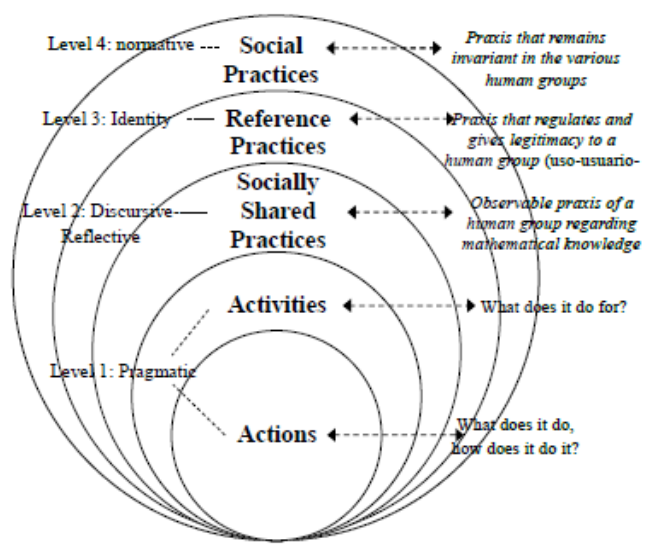

Figure 1 Nesting model of practices
Source: adapted from (Cantoral, Montiel y ReyesGasperini, 2015, p. 13)

In particular, we take the first level of the nesting model: pragmatic to qualitatively analyze the social construction of mathematical knowledge that is given, and from it infer the context of significance. The direct action of the subject (individual, collective or historical) before the milieu is analyzed by questioning from the "what does" and the "how does it", in its relation to the mathematics at stake; and with the articulation of actions, response is given to the "what it does for", configuring a culturally located activity (Cantoral, Reyes-Gasperini y Montiel, 2015).

\section{Social construction of trigonometric knowledge}

Montiel (2011) identified in a historicalepistemological analysis that the problem of astronomers to calculate inaccessible distances of non-manipulable objects (sun, moon, planets, etc.) was the emergency scenario of the trigonometric problem, which they solved by modeling macro (object) with the micro (model) in a geometric context. Therefore, it is recognized as the social nature of Trigonometry to the study and quantification of the nonproportional relationship 'central anglesubtended string', in the circle; which would be equivalent to the study of the non-proportional opposite-adjacent angle-leg ratio in the right triangle (figure 2).

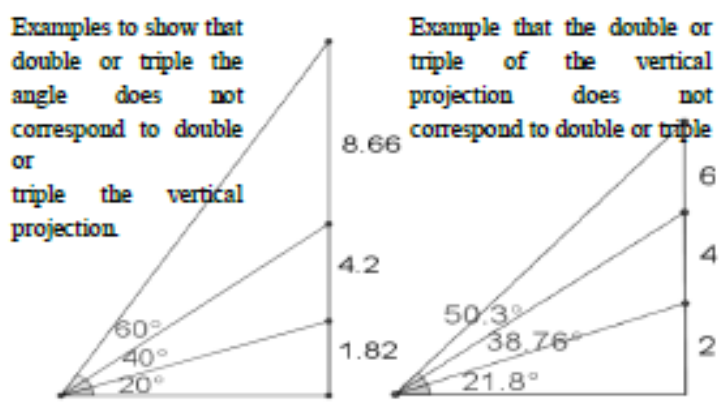

Figure 2 Trigonometric relationship Source: adapted from (Cantoral, Montiel and ReyesGasperini, 2015, p. 17)

The adaptations for Trigonometry to be taught have established as a School Mathematical discourse: to study the relationship between the lengths of the sides in the right triangle. 
Thus, solving an exercise or problem consists in giving the student a drawing of a triangle with sufficient measures to identify the data, choose the right reason for the situation, replace the data in the calculator and obtain a unique missing value, converting trigonometric knowledge only in an application of the proportional; and as a consequence devoid of the geometric context, which has caused, for example, the difficulty of not conceiving the variation of the angle because there is a case (drawing) that is not reflected that varies.

This teaching has allowed learning, but it has caused a didactic phenomenon that Montiel (2011) calls trigonometric arithmetization, which refers to the loss of the geometric process where the angle-leg ratio arises. The study with the right triangle is not the cause itself, but what is promoted by the student with it: a mathematical activity devoid of taking measurements, developing models (to scale or sketches) of triangles, making relationships between its sides and angles, and reflect if the calculations obtained are congruent with the triangle.

The learning that has been documented with this type of teaching admits the construction of a linear meaning (figure 3 ), both in students and in teachers: consider that the leg (the adjacent one in figure 3 ) and the angle grow or decrease in shape constant (Montiel and Jácome, 2014), as opposed to the nonproportional nature of the trigonometric relationship.

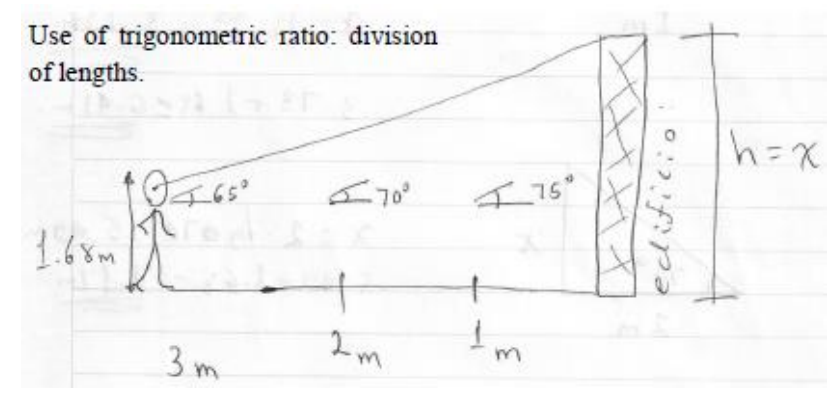

Figure 3 Significado lineal

Source: adapted from (Jácome, 2011, p. 126)

From the study of Montiel (2011), an epistemological hypothesis is configured for the social construction of the trigonometric, which has been the basis for various didacticexperimental studies, proposing that: studying its nature implies identifying the nonproportional of this relationship (the trigonometric ratio).
But analyze and quantify it with the proportional (trigonometric ratio), in mathematical activity of geometric construction. Hence, for the design or didactic analysis, we start from the following elements of social construction of trigonometric knowledge (Cantoral, Montiel and Reyes-Gasperini, 2015): (1) measure and reflect on proportionality, (2) build models ( to scale or sketches), (3) model the passage from the macro (real object) to the micro (model) and (4) make relationships of the 'angle - length in the triangle or string in the circle'.

In the search to counteract this linear meaning, didactic-experimental studies have been carried out with students from the upper middle (Scholz and Montiel, 2015) and higher (Torres-Corrales, Montiel and Cuevas, 2015), where the most relevant thing was to identify that by integrating Geometric construction processes for the resignification of trigonometric reason, this is accompanied by various mathematical reasoning (empirical, arithmetic, algebraic and geometric) and occurs naturally, the articulation with other mathematical knowledge; reasoning understood as the ways of acting before a problem.

\section{Ethnographic Method}

Our study is qualitative, non probabilistic, and given the research problem in conjunction with the access and facilities that the university has provided to the project we opt for the ethnographic method (table 1), which we configure in five stages, organized in three moments.

\begin{tabular}{|l|l|}
\multicolumn{1}{|c|}{ Moment } & \multicolumn{1}{c|}{ Stage } \\
\hline I. Collection & $\begin{array}{l}\text { 1. Stage Documentation } \\
\text { 2. Planning field work }\end{array}$ \\
\hline II. Production & 3. Field work \\
\hline III. Analysis & $\begin{array}{l}\text { 4. Descriptive analysis } \\
\text { 5. Qualitative analysis of mathematical } \\
\text { activity }\end{array}$ \\
\hline
\end{tabular}

Table 1 Ethnographic research method Source: built from (Geertz, 2006; Hammersley and Atkinson, 1994; Rodríguez-Gómez and Valldeoriola, 2012)

During the moment I, a documentation was carried out (stage 1) with the non-participant observation technique and analytical tools of the ST to indirectly study the mathematical culture through the review of documentary sources. 
The purpose was to preliminary understand the knowledge (mathematical and disciplinary) related to the direct kinematic problem. Also, during the moment I, the field work was planned (stage 2) where we chose the techniques and designed the instruments to record the data during stage 3; In addition, we design a work plan and formats for consent and data processing.

At the moment II we carry out the field work (stage 3) where we use and adjust the designed instruments. With the participant observation technique (Hammersley and Atkinson, 1994) we study broad aspects of culture from its natural context (as a native does), and to record the data we use two instruments: notebook and field diary, the first allowed to document each class session and the second to reflect on the development of the topics discussed and the participants' actions.

Also, we use the conversation technique (Rodríguez-Gómez, 2016) in order to contrast what was observed. The modalities were: discussion group with which we generated a wide range of ideas, opinions and experiences around the object of study, and individual interview when it was necessary to approach and understand the assumptions of the person interviewed; for both semi-structured interview scripts were used.

The combination of techniques and instruments constitutes the triangulation strategy, which allows them to be compared and compared, providing the study of rigor and quality (Rodríguez-Gómez and Valldeoriola, 2012); To ensure the objectivity and ethics of the study, the field work was followed by two academics from the target institution: tutor, who gave methodological follow-up to the work plan, and co-tutor, who received in his Industrial Robotics classes a the principal investigator (first author), validated the interpretation of disciplinary knowledge and gave consent to make the registered information public.

The project is currently at the moment III, with the descriptive analysis (stage 4) the cultural and situational contexts were characterized by a dense description (in the sense of Geerz, 2006); and with the analysis of the mathematical activity (stage 5) the uses of trigonometric knowledge were obtained and inferred the context of significance, based on which we responded to the research question.
In this paper we delve into the moment III, in particular we show an example of the qualitative analysis of the mathematical activity of a robot with which we infer the context of significance and accompany it from the cultural and situational contexts.

\section{Results}

\section{Cultural context}

In stage 1 with the non-participant observation we review various sources to prepare the documentation: specialized engineering journals, some Internet sites (wikis, blogs, videos, etc.), Handbooks (disciplinary manuals) and books. From here we identify Mechatronics Engineering as a reference practice, as it will provide the engineer with identity and regulate his work in Robotics: he will be responsible for the synthesis of aspects of the functioning of the human body (Craig, 2006; Siciliano and Khatib , 2016) through the design and analysis of robots, through mechanisms, sensors, actuators and computers (Spong, Hutchinson and Vidyasagar, 2004; Saha, 2010).

In stage 3 with the participant observation technique, we documented the behavior of the students and the teacher for 55 hours through 42 notebooks, 4 field diaries and with complementary records (71 audios, 24 videos and 196 photographs). From here we identify that Mechatronics Engineering uses and builds various models to study the problems it solves: direct kinematics, reverse kinematics and speed analysis. In particular for the direct kinematic problem, where there was the greatest variety of models, these were used as representations to simplify, systematize and study the robot's movements through disciplinary and mathematical knowledge; and although they were drawings (without scale), they allowed them to relate and analyze some element of Robotics.

In this cultural context of the mechatronics engineer, for the purposes of our object of study, we identify three essential aspects: the circular movement, which is generated thanks to a rotational kinematic pair, the displacement by a prismatic pair, and the mathematical modeling process that is gives to model the transition from the macro (robot) to the micro (model). 
In particular, the circular movement and the construction of diagrams, because they are part of the context of significance of the trigonometric found in historicalepistemological studies.

\section{Situational context}

Also during stage 3 with the participant observation we document some characteristics of the participants and their roles in the Industrial Robotics classes. The project was carried out in a Mechatronics Engineering community of the Technological Institute of Sonora (ITSON), a public and decentralized university located in northern Mexico. The field work was during the August-December 2018 semester with students of the 2009 plan who were studying Industrial Robotics, a subject located in the seventh of nine semesters, which is composed of a theory class (3 hours a week) and a laboratory ( 2 hours a week, operating robots operation).

47 students participated (42 men and 5 women), who were between 21 and 24 years old, and a tenured professor who taught both classes; The teacher has an academic training for a bachelor's degree, masters and doctorate in the same discipline and has working and teaching experience in that engineering field.

The theory was taught in two different classrooms equipped with a computer, projector, door with sensors that are operated with an electronic card and two air conditioners (they generate high levels of ambient noise). For the explanation of the classes the teacher used the support of the board in two modalities: written notes and projected notes of a presentation, while the students took notes in their notebooks and / or photographs.

The teacher's explanation (figure 4) was aided by body mevements (hip, shoulder, elbow, wrist and hand) to represent the movements of the robot. He also used four colored markers (black, blue, red and green) to emphasize the notes he made and to represent the movement of axes and linkages; in a consistent way the professor resumed the laboratory practices, assignments, previous sessions topics and some previous subjects for his explanations, in addition to mentioning the technical terms in Spanish and English.

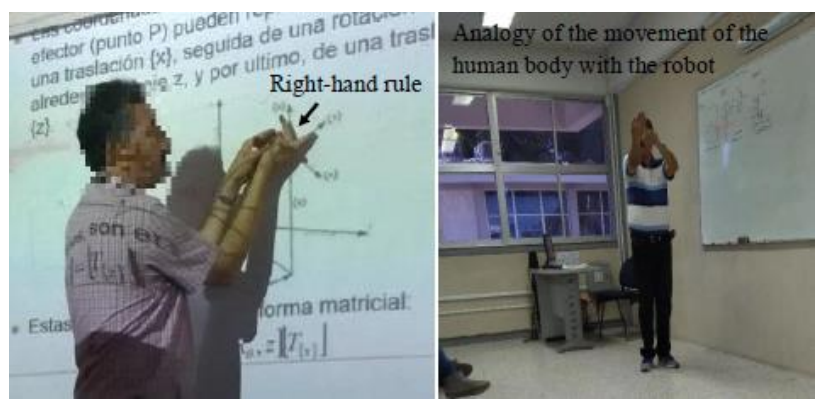

Figure 4 Explanations of the teacher in theory Source: photographs of (field work, 2018)

The laboratory was taught in a classroom with three industrial robots of four, five and six degrees of freedom; equipped in accordance with safety regulations (for example, safety signs, smoke detectors and first aid kit).

In the laboratory class there were two behaviors: explanation and practice. In the explanation, the professor presented the content of the practice, what it is intended to achieve and comments at the technical level; the students attended the teacher's explanation, and some made comments and / or questions. In the realization, the students (individual or team) manipulated the robot through the teach pendant following the instructions of the manual under the supervision and evaluation of the teacher (figure 5).

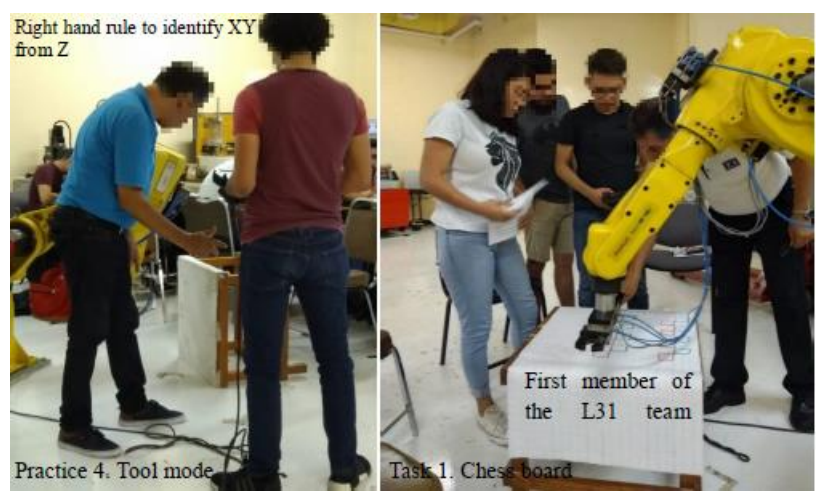

Figure 5 Realization of laboratory practices Source: photographs of (field work, 2018)

Consistently the students: (a) while a student manipulated the robot the rest of the team gave directions or suggestions to their partner in turn, (b) made comments between classmates to validate what they understood or resolve doubts before programming and executing any movement, (c) physically made the rule of the right hand before giving instructions, and (d) at the end of the session a different student performed the shutdown routine to return it to the geometric resting configuration indicated by the manufacturer. 
In addition, all laboratory practices were conducted limiting its speed to a $50 \%$ of its maximum, in order to maintain student safety.

In this situational context of the mechatronics engineer in training, for the purposes of our object of study, we identify two essential aspects in the theory and the laboratory: the body movement to explain the movement of the robot, and the rule of the right hand that was used to differently even by the same person, because it depended on the physical conditions of the problem: a certain movement of the hand is more natural if it is an object embodied in a surface (2D, blackboard, book or notebook) or in space (3D, at manipulate the robot).

\section{Mathematical activity analysis}

Also, with the participant observation we document what the teacher and the students did to solve the direct kinematic problem. We take the case of the solution of the SCARA robot (robotic arm for selective trust assembly), through the six-step method, an adaptation and interpretation of the teacher (M. Herrera, personal communication, 22 / 10/2018) of the article by Denavit and Hartenberg (1955).

In steps 1 and 2 (figure 6) they developed pseudo concrete models (drawing and scheme) to select the variables of interest of the robot.

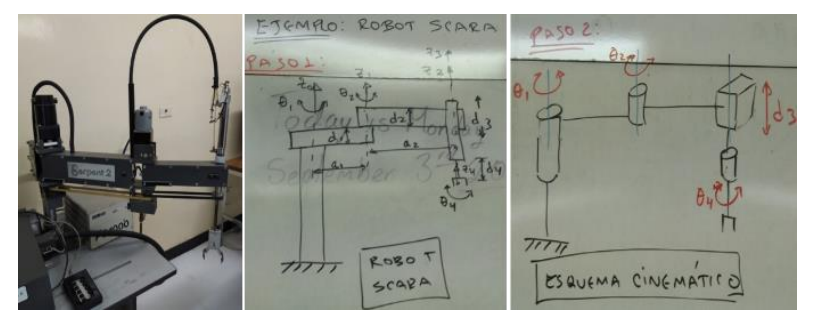

Figure 6 Steps 1 and 2

Source: (photographs of fieldwork, 2018)

In step 1 they articulated two reasonings: (1) the spatial, made the change from $3 \mathrm{D}$ to $2 \mathrm{D}$ for the drawing; and (2) graph, elaborated the drawing and identified that the robot has all the axes $\left(z_{0}, z_{1}, z_{2}, z_{3}\right)$ parallel. While in step 2 they articulated the reasoning: (1) spatial, they made the change from 2D (drawing) to 3D (geometric figures) and pointed out the direction (turn or slip) of each pair; and (2) geometric, they represented the degrees of freedom of rotating pairs $\left(\theta_{1}, \theta_{2}, \theta_{3}\right)$ by means of a rectangular cylinder and for the translation pairs (sliding, $\mathrm{d}_{1}$ ) with a rectangular prism.
And identified that the volume of Work generates a straight rectangular cylinder. For both steps they used the angle as quality (shape) in their dynamic character (turn).

Therefore, in steps 1 and 2 the construction of visual referents and modeling is manifested when they draw up the drawing and the kinematic scheme, and with them they model their movement, to perform the activity of identifying the axes, the quantity and types of pairs kinematics, and visualize the workspace; only the measurement is not given in the theory class, although in the laboratory class where the students took measurements with a flexometer and compared them with the robot's technical data sheet.

In steps 3 to 5 they developed new mathematical models: vectors, parameter tables and matrices of elements; that require establishing coordinate systems and calculating the resulting homogeneous linear transformation matrix. The validation of the mathematical result was carried out with the models elaborated in steps 1-3 and the Theory of Machines and Mechanisms to ensure that it was mechanically consistent with the movement.

In step 3 (which they also called a wire diagram) they articulated two reasonings: (1) the graph, assigned a coordinate system to each element systematically following the algorithm and the rule of the right hand.

With (2) metric reasoning, for rule 1 they assigned the $\mathrm{Z}_{\mathrm{i}}$ axis of each link with the direction of movement allowed in the pair, and for rule $2 \mathrm{a}$ they assigned the $\mathrm{x}_{\mathrm{i}}$ axis as a perpendicular segment to $\mathrm{z}_{\mathrm{i}}$ and $\mathrm{z}_{\mathrm{i}-1}$ (figure 7 ).

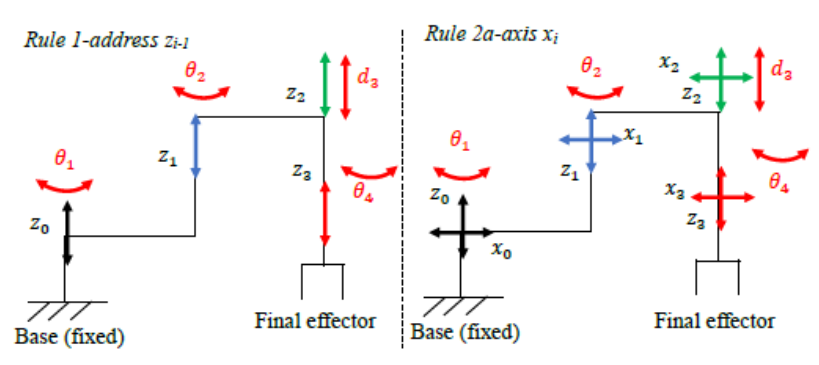

Figure 7 Rules 1 and 2a Source: Our Construction

For rule $2 b$, they chose the positive direction of the $x_{i}$ and $z_{i}$ axes, indicating the individual movement of the pair, which indicated that it would facilitate the calculations. 
For rule 3 they assigned the $y_{i}$ axis forming a tri-rectangle trihedron with the right hand ruler: on the $z_{i}$ axis the 4 fingers were upright, as the $\mathrm{x}_{\mathrm{i}}$ axis turned the 4 fingers towards the palm of the hand and pointed like the $\mathrm{y}_{\mathrm{i}}$ axis where the thumb pointed; finally for rule 4 they placed the origin at the intersection of the common normal between the axes (figure 8).

Therefore in step 3, the use of angle is given as a quality in its dynamic character; and the construction of visual referents and modeling is manifested when they elaborate the coordinate systems diagram because they generate a metric to study the problem and with it they model the direction and sense of the elements with respect to the adjacent element, to perform the activity of establish a particular kinematic configuration of the robot.

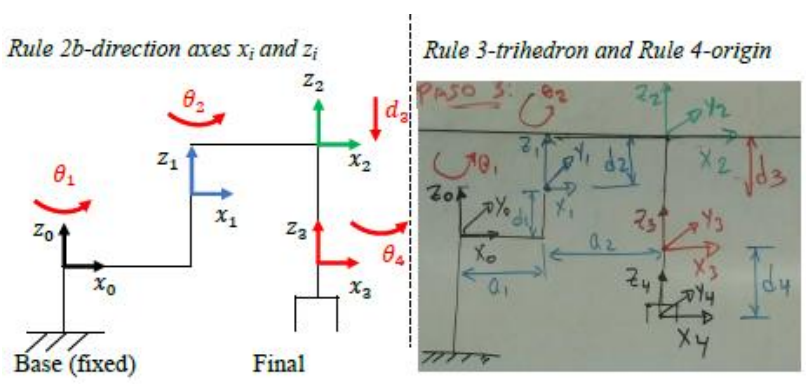

Figure 8 Rules 2b, 3 and 4

Source: (our construction and photography of field work, 2018 , respectively)

In step 4 (figure 9) they articulated five reasonings: (1) the spatial, when they identified for each element and its adjacent, axes, angles and distances; (2) the metric, when establishing lengths by means of the axis-axis relation; (3) the graph, when they made relations between two adjacent links, for example, when the axes are parallel (collinear) the angle is zero and when the distance is cut it is zero; (4) the covariational, when they studied the angle-distance relationship of the elements across the axes; and (5) the quantitative, when they calculated the fixed or variable amount of the parameter recognizing its origin.

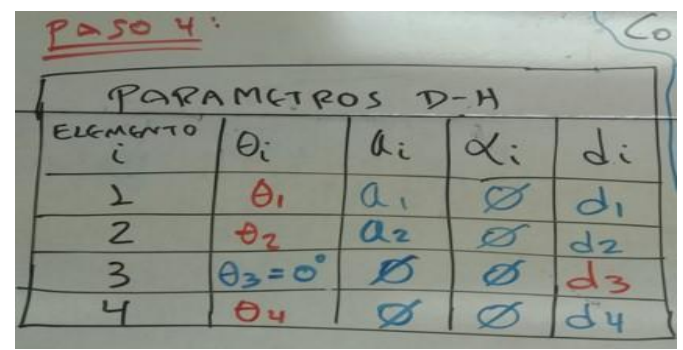

Figure 9 Step 4

Source: (photography of field work, 2018)

ISSN 2444-3204

ECORFAN@ All rights reserved
The kinematic torque angle $\left(\theta_{\mathrm{i}}\right)$ was determined as the one formed between the $\mathrm{x}_{\mathrm{i}-1}$ and $\mathrm{x}_{\mathrm{i}}$ axes around $\mathrm{z}_{\mathrm{i}-1}$, and only exists when it does not coincide with $x_{i}$; the length of the element $\left(\mathrm{a}_{\mathrm{i}}\right)$ was measured from the intersection of the $\mathrm{z}$ axis (i-1) with the $\mathrm{x}_{\mathrm{i}}$ axis to the origin of the reference system of the element (i); the torsion angle of the element $\left(\alpha_{i}\right)$ was established as that formed between the $\mathrm{z}_{\mathrm{i}-1}$ to $\mathrm{z}_{\mathrm{i}}$ axes around the $\mathrm{x}_{\mathrm{i}}$ axis; and finally the distance between pairs $\left(d_{i}\right)$ was measured from the origin of the reference system of the element (i-1) and the point of intersection of the $\mathrm{z}$ axis (i-1) with the $\mathrm{X}_{\mathrm{i}}$.

Therefore, in step 4, the use of the angle is given as relation ( $\mathrm{x}$-axis, $\mathrm{y}$ or $\mathrm{z}$ ) and quantity (variable), both in its static and dynamic character; static by the case study, when the angle is an inclination with respect to the adjacent and dynamic element because it changes with the movement of the robot.

Also, they made relationships of perpendicularity, parallelism, turns and displacements in the diagram of step 3 , where the variable values were placed in red and the constants in blue; and they carried out the activity of identifying the value of the four parameters (two angles and two distances) of the kinematics of the problem and organized them in a table.

In step 5 (figure 10), with the algebraic reasoning they developed the matrices of elements taking up the value of the parameters of step 4, and the use of the angle was given as quantity (variable).

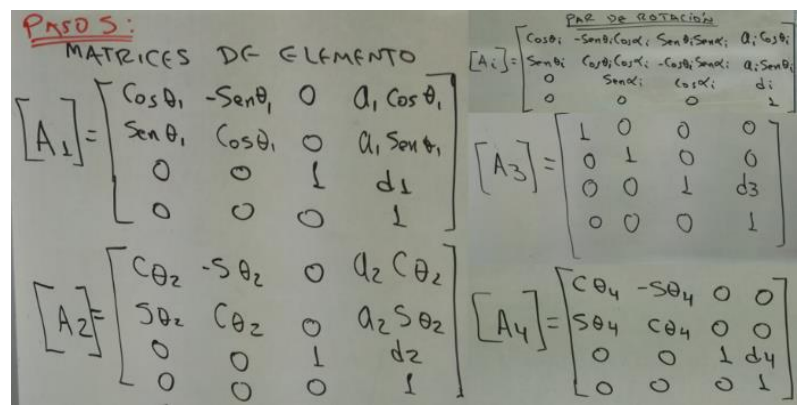

Figure 10 Step 5

Source: (photography of field work, 2018) 
In step 6 (figure 11), with the algebraic reasoning they calculated the homogeneous linear transformation matrix from performing the operations with the matrices of elements in the order of the robot's movement, justifying that in the case of mobile systems the transformation matrix it is written from left to right.

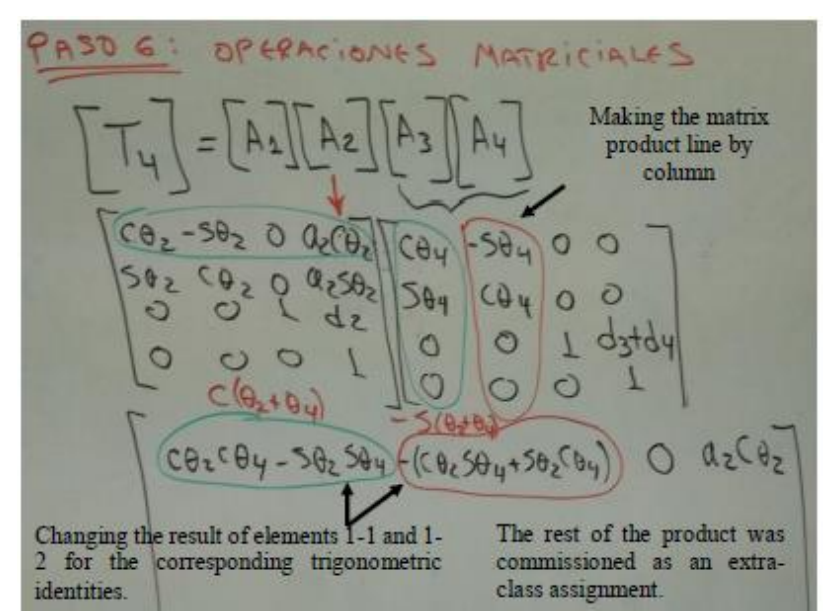

Figure 11 Step 6

Source: (photography of field work, 2018)

In particular:

They started operations by the matrices $\left[\mathrm{A}_{3}\right]\left[\mathrm{A}_{4}\right]$ and commented that since $\left[\mathrm{A}_{4}\right]$ is the identity matrix, the product was not required because it would give the same result, except element 3-4 where they added $d_{3}+d_{4}$;

They wrote the matrix $\left[\mathrm{A}_{2}\right]$ indicating that it was going down with an arrow to multiply it by the result of the matrices $\left[\mathrm{A}_{3}\right]\left[\mathrm{A}_{4}\right]$, from which they made the product to obtain row 1 , the rest of the operations were carried out as an extra assignment. Class;

And the result of row 1 of the matrices $\left[\mathrm{A}_{2}\right] \quad\left[\mathrm{A}_{3}\right] \quad\left[\mathrm{A}_{4}\right]$ changed it to trigonometric identities justifying the need to simplify operations to avoid the lag between the response time of the control (must be faster) and the mechanical of the robot.

Finally, in step 6 they validated the resulting transformation matrix with the previous diagrams (step 1-3) to confirm that the mathematical result was congruent with the proposed kinematic configuration for the robot, that is, that the position vector be mechanically congruent with the movements. They also used the angle as relation and quantity (variable), both in the static and dynamic character.
With the particular kinematic configuration, in the static character they considered the angle as a scope in the total transformation of the base with respect to the final effector and with the dynamic one that can be variable by the movement of the robot.

\section{Discussion}

By doing a cross-sectional analysis of the sixstep method to solve the direct kinematic problem, we can characterize the complete mathematical modeling process that Mechatronics Engineering does (figure 12).

\begin{tabular}{|c|c|c|}
\hline \multirow{4}{*}{$\begin{array}{l}\text { Real situation } \\
\text { Industrial robot (physical, } \\
\text { technical sheet or photo) } \\
\text { Local geometric } \\
\text { configuration }\end{array}$} & te & $\longrightarrow$ Mathematical model \\
\hline & Model & $\begin{array}{l}\text { Step 3: Coordinate systems (wire } \\
\text { diagram) }\end{array}$ \\
\hline & Step 1: Robot drawing & $\begin{array}{l}\text { Step 4: Denavit-Hartenberg } \\
\text { parameter table }\end{array}$ \\
\hline & Step 2: Kinematic scheme & Step 5: Element Matrices \\
\hline End-base effector relationship & & $\downarrow \begin{array}{c}\text { Matrix operations and } \\
\text { trigonometric identities }\end{array}$ \\
\hline $\begin{array}{l}\text { Model-Reality } \\
\text { Confrontation }\end{array}$ & $\begin{array}{l}\text { Pseudo-Concrete } \\
\rightarrow \quad \text { Results }\end{array}$ & Mathematical Study \\
\hline $\begin{array}{l}\text { Mathematical-mechanical } \\
\text { congruence }\end{array}$ & $\begin{array}{l}\text { Machine and Mechanism } \\
\text { Theory }\end{array}$ & $\begin{array}{l}\text { Step 6: Homogeneous linear } \\
\text { transformation matrix }\end{array}$ \\
\hline Real Domain & Pseudo-Concrete Domain & Mathematical Domain \\
\hline
\end{tabular}

Figure 12 Mathematical modeling process of the direct kinematic problem

Source: built from (Rodríguez-Gallegos, 2010, p. 197)

In this process we recognize that there were three of the four elements of social construction of trigonometric knowledge that point out (Cantoral, Montiel and ReyesGasperini, 2015): build geometric models (sketches), model the transition from the macro to the micro and make relations of 'length-length and angle-distance of the robot elements through the axes'; only the measurement was not given as such because the data were given or established based on the Denavit-Hartenberg algorithm.

Of the elaborated models, we recognize as a geometric model the kinematic scheme (step 2 ), and although it was not to scale but a drawing of geometric figures (cylinder and prism), with this they established the type of movement allowed by the kinematic pair (turn or move) and identified the geometric configuration generated by the robot (a rectangular cylinder).

Although in steps 1-4 there was no use of trigonometric notions, actions and activities were manifested that allowed them to contextualize the problem of Robotics to the scenario of Kinematics, and later, in steps 5 and 6 , to mathematize it. 
In the problem of the SCARA robot we identify that there are four uses of the trigonometric notions to perform the activity of calculating the position and orientation of the final effector with respect to the base: (1) arithmetic of the sine and cosine ratios of the angle when dividing lengths to set the values of the rotation matrix; (2) metric of the angledistance and distance-distance relationship when calculating the four parameters of the algorithm with the axis-axis relationship; (3) quantitative and algebraic of the matrices of elements when recognizing the origin and operating fixed amounts and symbolic variables; and (4) algebraic identities double an angle and Pythagorean by simplifying the operations performed by the control for the balance of the mechanical part.

By identifying these uses of trigonometric notions, we identify that the context of significance is the construction of visual referents to model the problem in space; where the principal aspect is the circular movement (or sections of this one) and the composition of several of these along with the displacements, their representation and mathematization. In this process the right triangle "implicit" is a tool to determine the position, which like the coordinate systems are not provided or have their elements assigned a priori as it happens in the Basic Sciences.

Although a particular kinematic configuration of the robot is constructed (step 3), it is considered that it changes as the robot moves, which admits to recognize the static character with the particular case and with the movement the dynamic character of the angle, which allows attention to be maintained in the angle - position relationship, and this in turn is linked to the arithmetic use of the trigonometric ratio.

The uses of the angle are given as form, relation and quantity in this problem of Robotics, but unlike the Mathematics subjects (figure 3), as a relation it is defined and defined with respect to the axis indicated by the algorithm and not only to the preset by the given triangle; and as a quantity it can be fixed, when studying a particular case, or variable when considering the movement of the robot.
In the construction of visual referents, spatial reasoning prevailed, with which they studied the robot and its elements, either by changing from $2 \mathrm{D}$ to $3 \mathrm{D}$ and vice versa (steps 1 and 2), or by making perpendicularity relationships, parallelism, turns and displacements taking the observer perspective indicated by the Denavit-Hartenberg algorithm, in conjunction with the right hand rule (step 4).

Also, with the fieldwork we identify that there is no single way to use the right hand rule, which allowed us to expand the documentation (stage 1) of the books of Physics and Linear Algebra: thumb points to the right (axis y), index up ( $\mathrm{z}$ axis) and middle finger to the heart ( $\mathrm{x}$ axis).

\section{Conclusions}

From the results of the participant observation, it was identified that to solve the direct kinematic problem, the Mechatronics Engineering community gives epistemic value to specific pseudo models, in contrast to what happens in the Mathematics subjects, where only the models are usually prioritized which include arithmetic, algebraic and analytical processes (Faulkner, Earl and Herman, 2019). Also, based on the results of the non-participant observation, we identify in these models the raison d'etre of Trigonometry as a Robotics tool: determination of the position in the circularity or circular sector. This implies movement, attending to particular cases (positions) and that gives a trigonometric ratio a context of broad significance.

Although we do not know the academic moment where the Mechatronics Engineering student develops the spatial reasoning that is used for the direct kinematics problem, it can be deduced that it is possible to acquire it through training because it is transferable and malleable to any stage of human development (Newcombe, 2010) ; Some tasks that encourage it are: symbolic representations (language, maps, diagrams, sketches and graphs), make analogies (similarities between phenomena) and gestures (move hands) (Newcombe, 2010). However, we identify in stage 1 that this type of reasoning is absent in the Mathematics subjects, where the trigonometric content to be used in the professionalizing subjects is addressed. 
In that sense, mathematics may be playing an obstacle role instead of potentializing a necessary STEM (Science, Technology, Engineering and Mathematics) skill required (Lowrie and Jorgensen, 2017).

In the data collection there were episodes where we identify, both in the teacher and in the student, actions or arguments that allude to the transcendent nature of the trigonometric quantity (or in the case of students, to a non-linear nature), related to its handling in the circle. Hence, identifying the context of significance where trigonometric reason is put into use provides us with elements to redesign School Mathematical discourse, as it points to possible situational contexts (designs) that do not favor or admit linear meaning (or the illusion of linearity, in the sense of De Bock, Van Dooren, Janssens and Verschaffel, 2007) when working with the relationship between an angle and the string or leg that subtends. We are analyzing these episodes in depth, as a way to support the uses and context of significance that we have identified and characterized with the SCARA.

In studying the uses of trigonometric notions from the Socioepistemological Theory we problematized the questioned mathematics what and how it is constructed and transmitted in particular scenarios; in this way mathematics was made part of the didactic phenomenon and the responsibility was only depersonalized only to the teacher or the student of the difficulties associated with their teaching and learning.

\section{References}

Bissell, C. y Dillon, C. (2012). Mathematical and Other Modelling in Engineering and Technology Ways of Thinking, Ways of Seeing. Alemania: Springer.

Cabañas, G. (2011). El papel de la noción de conservación del área en la resignificación de la integral definida. Un estudio socioepistemológico. Tesis de doctorado, México: Centro de Investigación y de Estudios Avanzados del Instituto Politécnico Nacional.

Cantoral, R., Farfán, R., Lezama, J. y MartínezSierra, G. (2006). Socioepistemología y representación: algunos ejemplos. Revista Latinoamericana de Investigación en Matemática Educativa (número especial), 83102.
Cantoral, R., Montiel, G. y Reyes-Gasperini, D. (2015). Análisis del discurso Matemático Escolar en los libros de texto, una mirada desde la Teoría Socioepestemológica. Avances de Investigación en Educación Matemática, 8, 928.

Cantoral, R., y Farfán, R. (2003). Matemática Educativa: Una visión de su evolución. Revista Latinoamericana de Investigación en Matemática Educativa, 6(1), 27-40.

Craig, J. (2006). Robótica. Tercera edición. México: Pearson.

De Bock, D., Van Dooren, W., Janssens, D. y Verschaffel, L. (2007). The Illusion of Linearity: from analysis to improvement. New York, USA: Springer.

Denavit, J. y Hartenberg, R. (1955). A kinematic notation for lower pair mechanisms based on matrices. Journal of applied mechanics, 77(2), 215-221.

Faulkner, B., Earl, K. y Herman, G. (2018). Mathematical maturity for engineering students. International Journal of Research in Undergraduate Mathematics Education, 5, 1-32.

Geertz, C. (2006). La interpretación de las culturas. Duodécima Edición. España: Gedisa.

Hammersley, M. y P. Atkinson (1994). Etnografía. Métodos de Investigación. Segunda Edición. Barcelona: Paidós.

Herrera, R. (1990). Crítica al modelo ortodoxo de la enseñanza de la ingeniería e ideas para su modificación. Tecnología en marcha, 10(1), 316.

Hinojos, J. y Farfán, R. (2017). Acerca de las nociones de estabilidad en electricidad, la relación entre el calor y la electricidad. Revista de História da Educação Matemática, 3(3), 68100.

Jácome, G. (2011). Estudio socioepistemológico a las relaciones trigonométricas en el triángulo rectángulo. Un acercamiento a los significados construidos por el profesor. Tesis de maestría, México: Centro de Investigación en Ciencia Aplicada y Tecnología Avanzada del Instituto Politécnico Nacional. 
Langereis, G., Hu, J. y Feijs, L. (2013). How to Introduce Matematical Modelling in Industrial Design Education? En G. Stillman, G. Kaiser, W. Blum y J. Brown (Eds.), Teaching Matematical Modelling: Connceting to Research and Practice (pp. 551-561). Países Bajos: Springer.

Lowrie, T. y Jorgensen, R. (2017). Equity and spatial reasoning: reducing the mathematical achievement gap in gender and social disadvantage. Mathematics Education Research Journal, 1-11.

Mendoza-Higuera, E., Cordero, F., Solís, M. y Gómez, K. (2018). El Uso del Conocimiento Matemático en las comunidades de Ingenieros. Del Objeto a la Funcionalidad Matemática. Bolema, 32(62), 1219-1243.

Montiel, G. (2011). Construcción de conocimiento trigonométrico. Un estudio socioepistemológico. México: Diaz de Santos.

Montiel, G. y Jácome, G. (2014). Significado trigonométrico en el profesor. Boletim de Educação Matemática, 28(50), 1193-1216.

Newcombe, N. (2010). Picture this: Increasing math and science learning by improving spatial thinking. American Educator, 34(2), 29-35.

Rodríguez-Gallegos, R. (2010). Aprendizaje y enseñanza de la modelación: el caso de las ecuaciones diferenciales. Revista Latinoamericana de Investigación en Matemática Educativa, 13(4-1), 191-210.

Rodríguez-Gómez, D. (2016). Capítulo II. La entrevista. En S. Fàbregues, J. Meneses, D. Rodríguez-Gómez y M. Paré (Coords), Técnicas de investigación social y educativa (pp. 97-155). Barcelona: Editorial UOC.

Rodríguez-Gómez, D. y Valldeoriola, J. (2012). Metodología de la investigación. España: Universitat Oberta de Cataluña.

Rotaeche, R. (2012). Construcción de conocimiento matemático en escenarios escolares. El caso de la angularidad en el nivel básico. Memoria predoctoral, Centro de Investigación en Ciencia Aplicada y Tecnología Avanzada del Instituto Politécnico Nacional. México.
Saha, S. (2010). Introducción a la robótica. Primera edición. México: Mc Graw Hill.

Scholz, O. y Montiel, G. (2015). Construcción de significados de las razones trigonométricas en el contexto geométrico del círculo. Acta Latinoamericana de Matemática Educativa, 28, 907-914.

Siciliano, B. y Khatib, O. (2016, Eds.). Springer Handbook of Robotics. Alemania: Springer.

Spong, M., Hutchinson, S. y Vidyasagar, M. (2004). Robot dynamics and control. Segunda edición. Singapore: John Wiley \& Sons.

Torres-Corrales, D., Montiel, G. y Cuevas, O. (2015). Un entorno geométrico para la resignificación de las razones trigonométricas en estudiantes de ingeniería. Acta Latinoamericana de Matemática Educativa, 28, 890-898.

Tuyub, I. y Buendía, G. (2017). Gráficas lineales: un proceso de significación a partir de su uso en ingeniería. Revista de Investigación Educativa de la Rediech, 8(15), 11-28. 